\title{
Morphological Credentials of Afla-Toxigenic and Non-Toxigenic Aspergillus Using Polyphasic Taxonomy
}

\author{
A.A. Bharose, H.P. Gajera*, Darshna G. Hirpara, V.H. Kachhadia and B.A. Golakiya \\ Department of Biotechnology, College of Agriculture, Junagadh Agricultural University, \\ Junagadh, 362001, Gujarat, India \\ *Corresponding author
}

\begin{tabular}{|c|c|}
\hline & A B S T R A C T \\
\hline & The study was performed for development of macro and micro morphological characters \\
\hline Keywords & $\begin{array}{l}\text { of Aspergllius isolated from groundnut seeds, groundnut cake and soll using cultural and } \\
\text { microscopoic methods. Fungus colonies was inoculated in different media like Potato }\end{array}$ \\
\hline $\begin{array}{l}\text { Dogs, Epidural } \\
\text { anaesthesia, } \\
\text { haemodynamics, } \\
\text { Electrocardio- } \\
\text { graphic changes. }\end{array}$ & $\begin{array}{l}\text { Dextrose Agar (PDA) and Yeast Extract Sucrose (YES) Agar and compared with standard } \\
\text { cultures. The Aspergillus isolates grown on both medium were identified using } \\
\text { macroscopic characteristics such as colony color, colony reverse color, colony edge, } \\
\text { mycelia color, conidation, shape of conidia, conidial wall, mycelium growth, mycelium } \\
\text { growth rate and microscopic characteristics including vesicle diameter, conidiophore } \\
\text { width, length of conidia head and ascospore diameter. According to colony colour, }\end{array}$ \\
\hline Article Info & pigmentation and length of conidial head, the 21 isolates were identified as Aspergillus \\
\hline $\begin{array}{l}\text { Accepted: } \\
20 \text { February } 2017 \\
\text { Available Online: } \\
10 \text { March } 2017\end{array}$ & $\begin{array}{l}\text { species viz., A. flavus }(06)(200-800 \mu \mathrm{m} \text { conidial head length), A. tamarii }(05)(250-700 \\
\mu \mathrm{m}) \text {, A. flavus var. columnaris }(05)(500-1200 \mu \mathrm{m}) \text {, A. sojae }(02)(300-900 \mu \mathrm{m}) \text {, A. } \\
\text { parasiticus }(01)(350-900 \mu \mathrm{m}) \text {, A. niveus }(01)(250-350 \mu \mathrm{m}) \text { and A. fumigatus }(01)(900- \\
950 \mu \mathrm{m}) \text {. This is the first report on identification and characterization of Aspergillus strains } \\
\text { based on length of conidial head on PDA medium. Fungal toxicity was anticipated based }\end{array}$ \\
\hline & $\begin{array}{l}\text { on aflatoxin detection using biochemical test. Out of } 21,08 \text { isolates were found to be afla- } \\
\text { toxigenic based on biochemical test. }\end{array}$ \\
\hline
\end{tabular}

\section{Introduction}

The groundnut, or peanut (Arachis hypogaea), is a species in the legume or "bean" family (Fabaceae). Groundnut is grown in nearly 100 countries. China leads in production of groundnut, having a share of about $41.5 \%$ of overall world production, followed by India $(18.2 \%)$ and the United States of America (6.8\%). In Europe, the leading producer is Greece, at roughly 2000 tons per year. India is one of the major exporting countries of groundnuts after china (Anonymous, 2013).
Groundnut contaminated with the mold Aspergillus flavus which produces a carcinogenic substance called aflatoxin. Aspergillus is a large genus composed of more than 180 accepted anamorphic species (Pitt et al., 2000), with teleomorphs described in nine different genera (Pitt et al., 2000). The genus is subdivided in 7 subgenera, which in turn are further divided into sections (Klich, 2007). 
As with fungi in general, Aspergillus taxonomy is complex and ever evolving. The genus is easily identified by its characteristic conidiophore, but species identification and differentiation is complex, for it is traditionally based on a range of morphological features. Macromorphological features which are considered include conidial and mycelial colour, colony diameter, colony reverse colour, production of exudates and soluble pigments, presence of sclerotia and cleistothecia.

Micromorphological characterization is mainly dependent on seriation, shape and size of vesicle, conidia and stipe morphology, presence of Hülle cells, and morphology of cleistothecia and ascospores (Klich, 2002). Furthermore, all these morphological features have to be determined under standardized laboratory conditions (Okuda et al., 2000), in order to obtain an accurate identification. In this contest several Aspergillus taxonomic keys and guides are available (Klich, 2002).

Aspergillus Subgenus Circumdati Section Flavi, also refered to as the Aspergillus flavus group, has attracted worldwide attention for its industrial use and toxigenic potential. Section Flavi is divided in two groups of species.

One includes the aflatoxigenic species $A$. flavus, A. parasiticus and A. nomius, which cause serious problems worldwide in agricultural commodities, and the other includes the nonaflatoxigenic species $A$. oryzae, A. sojae and A. tamarii, traditionally used for production of fermented foods in Asia (Kumeda and Asao, 2001).

The objectives of the study were to investigate and characterize the diversity and distribution of aflatoxigenic and non aflatoxigenic Aspergillus fungi associated with groundnut seeds, groundnut cake and soil.

\section{Materials and Methods}

\section{Collection of groundnut seeds, cakes and soil samples}

Groundnut seeds were collected from farmers fields of Saurastra region, Gujarat and groundnut cake obtained from oil industries for isolation of aflatoxin and non aflatoxin producing Aspergillus. Soil samples were collected from healthy and infected groundnut fields of Junagadh Agricultural University, Junagadh.

\section{Isolation of Aspergillus from ground nut seeds and cake}

For isolation of Aspergillus, groundnut seeds and cake were surface sterilizing with $0.5 \%$ sodium hypochloride solution. After surface sterilization samples were cut into two halves with sterile scrapple and inoculated onto specific medium $\left(\mathrm{K}_{2} \mathrm{HPo}_{4} 0.5 \mathrm{~g} \mathrm{~L}^{-1}, \mathrm{MgSo}_{4}\right.$ $0.5 \mathrm{~g} \mathrm{~L}^{-1}$,Peptone $0.5 \mathrm{~g} \mathrm{~L}^{-1}$, Yeast $0.5 \mathrm{~g} \mathrm{~L}^{-}$ ${ }^{1}$,Sucrose $20 \mathrm{~g} \mathrm{~L} \mathrm{~L}^{-1}$, Agar $17 \mathrm{~g} \mathrm{~L} \mathrm{~L}^{-1}$, after autoclaving add $25 \mathrm{mg} \mathrm{L}^{-1}$ antibiotic (Streptomycin sulfate) and Rose Bengal dye (Manjusha and Anita, 2013), while groundnut cake were inoculated as such on same media so as to grow Aspergillus only. The yellow/green colour grown colonies from plates were inoculated onto centre of fresh PDA medium to obtain pure culture of fungus.

\section{Isolation of fungi from soil sample}

One gram of soil was added into the tube containing $9 \mathrm{~mL}$ of sterile distilled water to obtain 1/10 dilution (stock solution) and a series of $1 / 00,1 / 1000,1 / 10,000$, and $1 / 100,000$ dilutions was prepared by adding $1 \mathrm{~mL}$ of solution to $9 \mathrm{ml}$ of sterile distilled water respectively (Waksman and Fred, 1922). The one $\mathrm{ml}$ of suspension from each dilution was transferred onto specific 
medium. The yellow/green colour grown colonies from plates were inoculated onto centre of fresh PDA medium to obtain pure culture of fungus (Johnston and Booth, 1983). Plates were incubated at room temperature for 7 days at $28^{0} \mathrm{C}$. All the pure cultures were derived by subsequent transformation of pure mycelia on PDA media. Pure cultures were maintained fresh and viable by periodic transfer on PDA medium (Schindler et al., 1967).

\section{Morphological characterization of Aspergillus species}

Aspergillus species were characterized according the genus Aspergilli (Raper and Fennell, 1965; Diba et al., 2007) and classification system (Gams et al., 1985). Aspergillus species were cultured on two differential media i.e. Potato Dextrose Agar (PDA) (Salleh and Sulaiman, 1984) and Yeast Extract Agar (YEA), suitable for both production of aflatoxin (Davis, et al., 1966). After seven days of incubation, plates (in triplicates) were observed for macroscopic characteristics such as colony diameter, colony colour, colony reverse colour colony edge, mycelial colour, conidiation, shape of conidia, conidiophore branching, Growth rate and conidial wall.

The microscopic characteristics including vesicle diameter, conidiophore width, conidia head and ascospore diameter. For microscopic characteristics slides were stained with cotton blue and mounted in lectophenol. Photographs were taken under Zeiss Axiocam Imager, model $\mathrm{Z} 2$ microscope. A morphological examination of species was first made with naked eye and at low magnification power of microscope after that detailed examination were done according to Raper and Fennell (1965) and Gams et al. (1985). All the morphological observations were recorded in 5 replications and standard deviation calculated.
Screening of aflatoxigenic and non aflatoxigenic Aspergillus based on biochemical test

Biochemical test using ammonium hydroxide was done to identify toxic strain among 21 isolates. In this method, the reverse side of colonies of toxin producing strains on potato dextrose agar (PDA) medium turns from yellow to pink immediately after exposure to ammonium hydroxide vapor (Saito and Machida, 1999).

\section{Results and Discussion}

A total of 21 isolates of microscopic fungi consisting of Aspergillus species were obtained from the ground nut seeds, cake and soil and colony morphology were recorded (Table 1). Based on microscopic characters, the isolates were identified as Aspergillus species, viz. A. flavus (06), A. tamarii (05), A. flavus var. columnaris (05), A. sojae (02), A. parasiticus (01), A.niveus (01), and $A$. fumigatus (01) (Fig. 8). The identified isolates were found similar in characters like smooth in colony edge, white mycelia colour, round conidia shape and smooth conidial wall on both PDA and YES media.

\section{Macro and micro-morphological descriptors of Aspergillus}

\section{A. flavus}

Colonies on PDA showed slow growth rate and attend $75 \mathrm{~mm}$ in diameter after seven days at $28^{\circ} \mathrm{C}$. Colony color on PDA showed variation in different strains, yellow to green, or dark green, reverse white or yellow (Fig. 1A-B). Colonies on YES showed fast growth rate and attend $90 \mathrm{~mm}$ in diameter after seven days at $28^{\circ} \mathrm{C}$. Colony color on YES yellowish green, reverse whitish orange or orange (Fig. 1 E-F) (Table 1). 
The Aspergillus isolates were subjected to observations under Zeiss Axiocam Imager, model Z 2 microscope. Conidial heads on PDA media were found to be $250-700 \mu \mathrm{m}$ in diameter and Conidiophore 3.50-11.50 $\mu \mathrm{m}$ in width. Vesicle upon maturity were globose with 30-65 $\mu \mathrm{m}$ in diameter. Ascospores were ranged from $2.0-8.0 \mu \mathrm{m}$ in diameter with smooth cell wall (Fig. 1 C-D). Conidial heads on YES media were found to be $165-900 \mu \mathrm{m}$ in diameter and Conidiophore 5.00-16.00 $\mu \mathrm{m}$ in width. Vesicle upon maturity were globose with diameter 23-80 $\mu \mathrm{m}$ in diameter. Ascospore were ranged from diameter 3.60$10.30 \mu \mathrm{m}$ in diameter with smooth cell wall (Fig. 1 G-H) (Table 2).

\section{A. tamari}

A. tamari colonies on PDA showed medium growth rate and attend $65 \mathrm{~mm}$ in diameter after seven days at $28^{\circ} \mathrm{C}$. Colony color on PDA was visualized as green or brown with mycelium white to dull white in colour. Reverse side of colonies were found white or cream in colour. (Fig. 2 A-B). A. tamari colonies on YES showed medium growth rate and attend 80 to $90 \mathrm{~mm}$ in diameter after seven days at $28^{0} \mathrm{C}$. Colony color on YES was visualized as greenish yellow or white or brown with reverse side orange or yellow or cream (Fig. 2 E-F) (Table 1).

Microscopy of Aspergillus isolates was performed under Zeiss Axiocam Imager, model Z 2 which measured Conidial heads on PDA media from $600-920 \mu \mathrm{m}$ in diameter and Conidiophore ranged from 5.50-12.50 $\mu \mathrm{m}$ in width. Vesicle appeared to be subglobose to globose with 37.00-68.00 $\mu \mathrm{m}$ in diameter. Ascospore resembled spherical, smooth and measured 4.00-8.10 $\mu \mathrm{m}$ in diameter (Fig. $2 \mathrm{C}$ D). Microscopy of Aspergillus isolates was performed under Zeiss Axiocam Imager, model Z 2 which measured Conidial heads on YES media from $240-2380 \mu \mathrm{m}$ in diameter and Conidiophore ranged from $6.00-15.50 \mu \mathrm{m}$ in width. Vesicle size was measured 31.00$80.00 \mu \mathrm{m}$ in diameter. Ascospore resembled spherical, smooth and measured 4.00-9.20 $\mu \mathrm{m}$ in diameter (Fig. 2 G-H) (Table 2).

\section{A. flavus var. columnaris}

Colonies on PDA showed fast growth rate and attend $85 \mathrm{~mm}$ in diameter after seven days at $28^{0} \mathrm{C}$. Colony color on PDA showed variation in different strains, green or brown, reverse white or cream (Fig. 3A-B). Colonies on YES showed fast growth rate and attend $90 \mathrm{~mm}$ in diameter after seven days at $28^{\circ} \mathrm{C}$. Colony color on YES yellowish creamiest brown or yellowish green, reverse whitish orange or yellow (Fig. 3 E-F) (Table 1).

A. flavus var. columnaris isolates were subjected to observations under Zeiss Axiocam Imager, model $\mathrm{Z} 2$ microscope. Conidial heads on PDA media measures 600$920 \mu \mathrm{m}$ in diameter where as Conidiophore width ranged from 5.50-12.50 $\mu \mathrm{m}$. Vesicle diameter measures in between 37.00-68.00 $\mu \mathrm{m}$ and Ascospore ranged 4.00-8.10 $\mu \mathrm{m}$ in diameter (Fig. 3 C-D). Conidial heads on YES media measures $200-2900 \mu \mathrm{m}$ in diameter where as Conidiophore width ranged from 9.00-16.50 $\mu \mathrm{m}$. Vesicle diameter measures in between 23.00-86.00 $\mu \mathrm{m}$ and Ascospore ranged 5.20-8.60 $\mu \mathrm{m}$ in diameter (Fig. $3 \mathrm{G}-\mathrm{H}$ ) (Table 2).

\section{A. sojae}

A. sojae colonies on PDA showed medium growth rate and attend $80 \mathrm{~mm}$ in diameter after seven days at $28^{0} \mathrm{C}$. Green colour colonies with white reverse colour were seen on PDA medium (Fig. 4 A-B). Colonies on YES showed fast growth rate and attend 90 $\mathrm{mm}$ in diameter after seven days at $28^{0} \mathrm{C}$. Colony color on YES brownish green or yellowish green, reverse cream or light orange (Fig. 4 E-F) (Table 1). 
A. sojae isolates were subjected to observations under Zeiss Axiocam Imager, model Z 2 microscope. Conidial heads on PDA media measured $350-800 \mu \mathrm{m}$ in diameter with 5.50-18.00 $\mu \mathrm{m}$ Conidiophore widths. Vesicle diameter measured 35.00$100.00 \mu \mathrm{m}$ in diameter and Ascospore found spherical in shape with rough walled and ranged 4.10-7.30 $\mu \mathrm{m}$ in diameter (Fig. $4 \mathrm{C}$ D). A. sojae isolates were subjected to observations under Zeiss Axiocam Imager, model Z 2 microscope. Conidial heads on YES media measured $300-930 \mu \mathrm{m}$ in diameter with $9.60-15.00 \mu \mathrm{m}$ Conidiophore widths. Vesicle diameter measured $30.00-60.00 \mu \mathrm{m}$ in diameter and Ascospore found spherical in shape with rough walled and ranged 4.50$7.60 \mu \mathrm{m}$ in diameter (Fig. $4 \mathrm{G}-\mathrm{H}$ ) (Table 2).

\section{A. parasiticus}

A. parasiticus colonies on PDA showed slow growth rate and attend $65 \mathrm{~mm}$ in diameter after seven days at $28^{\circ} \mathrm{C}$. Colony color on PDA showed yellow green front colour with cream to pale yellow on reverse (Fig. 5 A-B). A. parasiticus colonies on YES showed slow growth rate and attend $90 \mathrm{~mm}$ in diameter after seven days at $28^{\circ} \mathrm{C}$. Colony color on YES showed green colour on front with red on reverse side (Fig. 5 E-F) (Table 1).

Microscopy of A. parasiticus determined conidial heads, $350-600 \mu \mathrm{m}$ in diameter on PDA media. The size of Conidiophore width was determined 3.20-4.00 $\mu \mathrm{m}$ and Vesicle diameter of about 45.00-60.00 $\mu \mathrm{m}$. Ascospore ranged 5.40-8.10 $\mu$ in diameter (Fig. 5 C-D).

Microscopy of $A$. parasiticus determined conidial heads, $350-930 \mu \mathrm{m}$ in diameter on YES media. The size of Conidiophore width was determined $11.5-15 \mu \mathrm{m}$ and Vesicle diameter of about 55.00-80.00 $\mu \mathrm{m}$. Ascospore ranged 3.1-6.30 $\mu \mathrm{m}$ in diameter (Fig. $5 \mathrm{G}-\mathrm{H}$ ) (Table 2).

\section{A. niveus}

Colonies on PDA showed slow growth rate and attend $55 \mathrm{~mm}$ in diameter after seven days at $28^{\circ} \mathrm{C}$. Colony color on PDA showed variation in different strains, brown, reverse yellow (Fig. 6 A-B). Colonies on YES showed slow growth rate and attend $55 \mathrm{~mm}$ in diameter after seven days at $28^{\circ} \mathrm{C}$, Colony color on YES White, reverse orange (Fig. 6 E-F) (Table 1). Conidial heads on PDA media were found $300-500 \mu \mathrm{m}$ in diameter and Conidiophore 7.30-10.00 $\mu \mathrm{m}$ in width. Vesicle ranged $45.00-100.00 \mu \mathrm{m}$ in diameter whereas Ascospore measured 4.30-5.00 $\mu \mathrm{m}$ in diameter (Fig. 6 C-D).Conidial heads on YES media were found $230-370 \mu \mathrm{m}$ in diameter and Conidiophore 60.00-80.00 $\mu \mathrm{m}$ in width. Vesicle ranged $60.00-80.00 \mu \mathrm{m}$ in diameter whereas, Ascospore measured 4.5-8.5 $\mu \mathrm{m}$ in diameter (Fig. 6 G-H) (Table 2).

\section{A. fumigates}

A. fumigates colonies on PDA showed medium growth rate and attend $65 \mathrm{~mm}$ in diameter after seven days at $28^{\circ} \mathrm{C}$. Colony color on PDA showed front gray-green, reverse cream (Fig. 7 A-B). A. fumigates colonies on YES showed medium growth rate and attended $90 \mathrm{~mm}$ in diameter after seven days at $28^{\circ} \mathrm{C}$. Colony color on YES showed front yellowish green, reverse light orange (Fig. 7 E-F) (Table 1). Microscopy of experimental fungus reveled 250-430 $\mu \mathrm{m}$ diameter of Conidial heads on PDA media. Conidiophore width ranged from 5.00-10.50 $\mu \mathrm{m}$ in and Vesicle 30.00-36.00 $\mu \mathrm{m}$ in diameter. Ascospore measured 3.00-4.00 $\mu \mathrm{m}$ in diameter (Fig. 7 C-D). Microscopy of experimental fungus reveled 900-950 $\mu \mathrm{m}$ diameter of Conidial heads on YES media. Conidiophore width ranged from 12.00-21.00 $\mu \mathrm{m}$ in and Vesicle 53.00-60.00 $\mu \mathrm{m}$ in diameter. Ascospore measured 5.60-6.00 $\mu \mathrm{m}$ in diameter (Fig. 7 G-H) (Table 2). 
Table.1 Colony morphology of Aspergillus strains on PDA and YES matrix

\begin{tabular}{|c|c|c|c|c|c|c|c|c|c|c|c|c|}
\hline $\begin{array}{l}\text { Iso- } \\
\text { late } \\
\text { No. }\end{array}$ & Isolate code & $\begin{array}{l}\text { Type of } \\
\text { Media }\end{array}$ & $\begin{array}{l}\text { Colony } \\
\text { colour }\end{array}$ & $\begin{array}{l}\text { Colony } \\
\text { reverse } \\
\text { colour }\end{array}$ & $\begin{array}{l}\text { Colony } \\
\text { edge }\end{array}$ & $\begin{array}{l}\text { Mycelial } \\
\text { colour }\end{array}$ & Conidiation & $\begin{array}{l}\text { Shape } \\
\text { of } \\
\text { conidia }\end{array}$ & $\begin{array}{l}\text { Conidial } \\
\text { wall }\end{array}$ & \multicolumn{2}{|c|}{$\begin{array}{l}\text { Mycelium } \\
\text { Growth }\end{array}$} & $\begin{array}{l}(\mathrm{mm}) \\
\text { Growth } \\
\text { rate }\end{array}$ \\
\hline & & & & & & & & & & 3 day & 7 day & \\
\hline \multirow[t]{2}{*}{1} & \multirow{2}{*}{$\begin{array}{l}\text { JND-VAD- } \\
\text { VAD-GG45 }\end{array}$} & PDA & $\begin{array}{l}\text { Yellowish } \\
\text { Green }\end{array}$ & Orange & Smooth & White & Circular & Round & Smooth & 35 & 79 & Medium \\
\hline & & YES & $\begin{array}{l}\text { Creamiest } \\
\text { Brown }\end{array}$ & Cream & Smooth & White & $\begin{array}{l}\text { Spot ring } \\
\text { Like flat }\end{array}$ & Round & Smooth & 90 & 90 & Fast \\
\hline \multirow[t]{2}{*}{2} & \multirow{2}{*}{$\begin{array}{l}\text { RJD-UPA- } \\
\text { KUN-G2 }\end{array}$} & PDA & gray-Green & Yellow & Smooth & White & $\begin{array}{l}\text { Spot ring } \\
\text { Like flat }\end{array}$ & Round & Smooth & 90 & 90 & Fast \\
\hline & & YES & $\begin{array}{l}\text { Yellowish } \\
\text { Green }\end{array}$ & Yellow & Smooth & White & $\begin{array}{l}\text { Spot ring } \\
\text { Like flat }\end{array}$ & Round & Smooth & 75 & 90 & Fast \\
\hline \multirow[t]{2}{*}{3} & \multirow{2}{*}{$\begin{array}{l}\text { JAM-JKB- } \\
\text { BHA-GG20 }\end{array}$} & PDA & Green & Cream & Smooth & White & $\begin{array}{l}\text { Spot ring } \\
\text { Like flat }\end{array}$ & Round & Smooth & 50 & 90 & Medium \\
\hline & & YES & $\begin{array}{l}\text { Yellowish } \\
\text { Green }\end{array}$ & $\begin{array}{l}\text { Light } \\
\text { Orange }\end{array}$ & Smooth & White & $\begin{array}{l}\text { Spot ring } \\
\text { Like flat }\end{array}$ & Round & Smooth & 65 & 90 & Fast \\
\hline \multirow[t]{2}{*}{4} & \multirow{2}{*}{$\begin{array}{l}\text { JND-MEN- } \\
\text { MEN-GG41 }\end{array}$} & PDA & $\begin{array}{l}\text { Greenish } \\
\text { brown }\end{array}$ & Cream & Smooth & White & $\begin{array}{l}\text { Spot ring } \\
\text { Like flat }\end{array}$ & Round & Smooth & 35 & 90 & Medium \\
\hline & & YES & $\begin{array}{l}\text { Greenish } \\
\text { Brown }\end{array}$ & Cream & Smooth & White & $\begin{array}{l}\text { Spot ring } \\
\text { Like flat }\end{array}$ & Round & Smooth & 90 & 90 & Fast \\
\hline \multirow[t]{2}{*}{5} & \multirow{2}{*}{$\begin{array}{l}\text { DWK-DWK- } \\
\text { GG20 }\end{array}$} & PDA & Green & White & Smooth & White & $\begin{array}{l}\text { Spot ring } \\
\text { Like flat }\end{array}$ & Round & Smooth & 45 & 80 & Medium \\
\hline & & YES & $\begin{array}{l}\text { Yellowish } \\
\text { Green }\end{array}$ & $\begin{array}{l}\text { Light } \\
\text { Orange }\end{array}$ & Smooth & White & $\begin{array}{l}\text { Spot ring } \\
\text { Like flat }\end{array}$ & Round & Smooth & 40 & 80 & Medium \\
\hline \multirow[t]{2}{*}{6} & \multirow{2}{*}{$\begin{array}{l}\text { JND-MEN- } \\
\text { MEN-GG41 }\end{array}$} & PDA & $\begin{array}{l}\text { Greenish } \\
\text { Brown }\end{array}$ & White & Smooth & White & $\begin{array}{l}\text { Spot ring } \\
\text { Like flat }\end{array}$ & Round & Smooth & 65 & 90 & Medium \\
\hline & & YES & Brown & Cream & Smooth & White & $\begin{array}{l}\text { Spot ring } \\
\text { Like flat }\end{array}$ & Round & Smooth & 45 & 90 & Medium \\
\hline 7 & $\begin{array}{l}\text { JND-MISC- } \\
3\end{array}$ & PDA & Green & White & Smooth & White & $\begin{array}{l}\text { Spot ring } \\
\text { Like flat }\end{array}$ & Round & Smooth & 40 & 90 & Medium \\
\hline
\end{tabular}




\begin{tabular}{|c|c|c|c|c|c|c|c|c|c|c|c|c|}
\hline & & YES & $\begin{array}{l}\text { Yellowish } \\
\text { Green }\end{array}$ & Cream & Smooth & White & Circular & Round & Smooth & 60 & 90 & Fast \\
\hline \multirow[t]{2}{*}{8} & \multirow{2}{*}{$\begin{array}{l}\text { JND-MISC- } \\
2\end{array}$} & PDA & $\begin{array}{l}\text { Greenish } \\
\text { Brown }\end{array}$ & White & Smooth & White & $\begin{array}{l}\text { Spot ring } \\
\text { Like flat }\end{array}$ & Round & Smooth & 60 & 90 & Medium \\
\hline & & YES & $\begin{array}{l}\text { Yellowish } \\
\text { Green }\end{array}$ & Yelloe & Smooth & White & $\begin{array}{l}\text { Spot ring } \\
\text { Like flat }\end{array}$ & Round & Smooth & 90 & 90 & Fast \\
\hline \multirow[t]{2}{*}{9} & \multirow{2}{*}{$\begin{array}{l}\text { JND-MISC- } \\
1-G G 20\end{array}$} & PDA & Green & White & Smooth & White & $\begin{array}{l}\text { Spot ring } \\
\text { Like flat }\end{array}$ & Round & Smooth & 90 & 90 & Fast \\
\hline & & YES & $\begin{array}{l}\text { Brownish } \\
\text { Green }\end{array}$ & $\begin{array}{l}\text { Light } \\
\text { Orange }\end{array}$ & Smooth & White & $\begin{array}{l}\text { Spot ring } \\
\text { Like flat }\end{array}$ & Round & Smooth & 55 & 90 & Fast \\
\hline \multirow[t]{2}{*}{10} & \multirow{2}{*}{$\begin{array}{l}\text { DWK-DWK- } \\
\text { GG20 }\end{array}$} & PDA & Brown & White & Smooth & White & $\begin{array}{l}\text { Spot ring } \\
\text { Like flat }\end{array}$ & Round & Smooth & 55 & 90 & Medium \\
\hline & & YES & Brown & Yellow & Smooth & White & $\begin{array}{l}\text { Spot ring } \\
\text { Like flat }\end{array}$ & Round & Smooth & 50 & 90 & Medium \\
\hline \multirow[t]{2}{*}{11} & \multirow{2}{*}{$\begin{array}{l}\text { JND-MEN- } \\
\text { GUN-GG41 }\end{array}$} & PDA & Brown & White & Smooth & White & $\begin{array}{l}\text { Spot ring } \\
\text { Like flat }\end{array}$ & Round & Smooth & 45 & 75 & Medium \\
\hline & & YES & Brown & Cream & Smooth & White & Circular & Round & Smooth & 60 & 90 & Fast \\
\hline \multirow[t]{2}{*}{12} & \multirow{2}{*}{$\begin{array}{l}\text { RJD-UPA- } \\
\text { KUN-TJ37A }\end{array}$} & PDA & Green & Yellow & Smooth & White & $\begin{array}{l}\text { Spot ring } \\
\text { Like flat }\end{array}$ & Round & Smooth & 90 & 90 & Fast \\
\hline & & YES & $\begin{array}{l}\text { Yellowish } \\
\text { Green }\end{array}$ & Yellow & Smooth & White & $\begin{array}{l}\text { Spot ring } \\
\text { Like flat }\end{array}$ & Round & Smooth & 70 & 90 & Fast \\
\hline \multirow[t]{2}{*}{13} & \multirow{2}{*}{$\begin{array}{l}\text { RJD-DHO- } \\
\text { PAR-GG37 }\end{array}$} & PDA & $\begin{array}{l}\text { Dark } \\
\text { Green }\end{array}$ & Yellow & Smooth & White & Circular & Round & Smooth & 55 & 90 & Slow \\
\hline & & YES & $\begin{array}{l}\text { Yellowish } \\
\text { Green }\end{array}$ & Yellow & Smooth & White & Circular & Round & Smooth & 55 & 90 & Slow \\
\hline \multirow[t]{2}{*}{14} & \multirow{2}{*}{$\begin{array}{l}\text { RJD-DHO- } \\
\text { KAN-GG45 }\end{array}$} & PDA & Green & Yellow & Smooth & White & $\begin{array}{l}\text { Spot ring } \\
\text { Like flat }\end{array}$ & Round & Smooth & 50 & 90 & Medium \\
\hline & & YES & Green & $\begin{array}{l}\text { Whitish } \\
\text { Orange }\end{array}$ & Smooth & White & $\begin{array}{l}\text { Spot ring } \\
\text { Like flat }\end{array}$ & Round & Smooth & 55 & 90 & Fast \\
\hline \multirow[t]{2}{*}{15} & \multirow{2}{*}{$\begin{array}{l}\text { JND-MAN- } \\
\text { LIM-GG20 }\end{array}$} & PDA & $\begin{array}{l}\text { Dark } \\
\text { Green }\end{array}$ & Yellow & Smooth & White & Circular & Round & Smooth & 50 & 90 & Slow \\
\hline & & YES & Green & Red & Smooth & White & $\begin{array}{l}\text { Spot ring } \\
\text { Like flat }\end{array}$ & Round & Smooth & 90 & 90 & Fast \\
\hline
\end{tabular}




\begin{tabular}{|c|c|c|c|c|c|c|c|c|c|c|c|c|}
\hline 16 & \multirow{2}{*}{$\begin{array}{l}\text { JND-MAN- } \\
\text { LIM-GG20 }\end{array}$} & PDA & $\begin{array}{l}\text { Dark } \\
\text { Green }\end{array}$ & Yellow & Smooth & White & Circular & Round & Smooth & 65 & 90 & Slow \\
\hline & & YES & White & Orange & Smooth & White & Circular & Round & Smooth & 40 & 55 & Slow \\
\hline \multirow[t]{2}{*}{17} & \multirow{2}{*}{$\begin{array}{l}\text { DAT-DAT- } \\
\text { PAT-GG37 }\end{array}$} & PDA & Brown & Cream & Smooth & White & $\begin{array}{l}\text { Spot ring } \\
\text { Like flat }\end{array}$ & Round & Smooth & 55 & 75 & Medium \\
\hline & & YES & White & Orange & Smooth & White & Circular & Round & Smooth & 45 & 55 & Slow \\
\hline \multirow[t]{2}{*}{18} & \multirow{2}{*}{$\begin{array}{l}\text { JND-MEN- } \\
\text { MEN-TJ45 }\end{array}$} & PDA & Green & White & Smooth & White & $\begin{array}{l}\text { Spot ring } \\
\text { Like flat }\end{array}$ & Round & Smooth & 90 & 90 & Fast \\
\hline & & YES & $\begin{array}{l}\text { Greenish } \\
\text { Yellow }\end{array}$ & Orange & Smooth & White & $\begin{array}{l}\text { Spot ring } \\
\text { Like flat }\end{array}$ & Round & Smooth & 50 & 90 & Medium \\
\hline \multirow[t]{2}{*}{19} & \multirow{2}{*}{$\begin{array}{l}\text { JND- JND- } \\
\text { Cak-1 }\end{array}$} & PDA & Green & White & Smooth & White & $\begin{array}{l}\text { Spot ring } \\
\text { Like flat }\end{array}$ & Round & Smooth & 30 & 85 & Medium \\
\hline & & YES & $\begin{array}{l}\text { Greenish } \\
\text { Yellow }\end{array}$ & Orange & Smooth & White & $\begin{array}{l}\text { Spot ring } \\
\text { Like flat }\end{array}$ & Round & Smooth & 90 & 90 & Fast \\
\hline \multirow[t]{2}{*}{20} & \multirow{2}{*}{$\begin{array}{l}\text { JND- JAU } \\
- \text { HSS- } 1\end{array}$} & PDA & Brown & Cream & Smooth & White & $\begin{array}{l}\text { Spot ring } \\
\text { Like flat }\end{array}$ & Round & Smooth & 30 & 70 & Medium \\
\hline & & YES & Brown & Cream & Smooth & White & $\begin{array}{l}\text { Spot ring } \\
\text { Like flat }\end{array}$ & Round & Smooth & 90 & 90 & Fast \\
\hline \multirow[t]{2}{*}{21} & \multirow{2}{*}{$\begin{array}{l}\text { JND- JAU } \\
- \text { ISS-1 }\end{array}$} & PDA & Green & Light Gre & Smooth & White & $\begin{array}{l}\text { Spot ring } \\
\text { Like flat }\end{array}$ & Round & Smooth & 50 & 90 & Medium \\
\hline & & YES & Yellow & $\begin{array}{l}\text { Light } \\
\text { Brown }\end{array}$ & Smooth & White & $\begin{array}{l}\text { Spot ring } \\
\text { Like flat }\end{array}$ & Round & Smooth & 40 & 90 & Medium \\
\hline
\end{tabular}


Table.2 Microscopic descriptions of Aspergillus strains on PDA and YES matrix

\begin{tabular}{|c|c|c|c|c|c|c|c|c|c|c|}
\hline & \multicolumn{4}{|c|}{ PDA Medium $(\mu \mathrm{m})$} & \multicolumn{4}{|c|}{ YES Medium $(\mu \mathrm{m})$} & \multirow[b]{2}{*}{ Identified as } & \multirow[b]{2}{*}{$\begin{array}{l}\text { Afla- } \\
\text { toxigenic }\end{array}$} \\
\hline $\begin{array}{l}\text { Isolate } \\
\text { No. }\end{array}$ & $\begin{array}{l}\text { Vesicle } \\
\text { diameter }\end{array}$ & $\begin{array}{c}\text { Conidiophor } \\
\text { e } \\
\text { width }\end{array}$ & $\begin{array}{c}\text { Conidial } \\
\text { Head (length) }\end{array}$ & $\begin{array}{l}\text { Ascospore } \\
\text { Diameter }\end{array}$ & $\begin{array}{l}\text { Vesicle } \\
\text { diameter }\end{array}$ & $\begin{array}{l}\text { Conidiophore } \\
\text { width }\end{array}$ & $\begin{array}{c}\text { Conidial } \\
\text { Head (length) }\end{array}$ & $\begin{array}{l}\text { Ascospore } \\
\text { Diameter }\end{array}$ & & \\
\hline 1. & $54.44 \pm 16.12$ & $9.32 \pm 2.59$ & $833.36 \pm 87.45$ & $4.06 \pm 0.05$ & $34.33 \pm 0.62$ & $12.26 \pm 3.58$ & $527.95 \pm 167.97$ & $5.83 \pm 2.09$ & A.tamarii & - ve \\
\hline 2. & $43.81 \pm 8.26$ & $6.47 \pm 2.03$ & $713.36 \pm 183.08$ & $5.14 \pm 0.26$ & $27.57 \pm 3.67$ & $11.59 \pm 0.45$ & $221.29 \pm 32.75$ & $6.53 \pm 0.88$ & A.fumigatus & + ve \\
\hline 3. & $34.37 \pm 3.38$ & $7.75 \pm 2.60$ & $346.23 \pm 92.26$ & $3.66 \pm 0.54$ & $56.48 \pm 3.05$ & $16.00 \pm 4.61$ & $937.24 \pm 25.21$ & $7.01 \pm 1.69$ & A.flavus & + ve \\
\hline 4. & $38.51 \pm 6.05$ & $10.95 \pm 0.64$ & $548.64 \pm 220.21$ & $5.07 \pm 1.42$ & $52.12 \pm 15.06$ & $12.38 \pm 3.85$ & $833.71 \pm 259.82$ & $6.88 \pm 0.64$ & $\begin{array}{l}\text { A.flavus var. } \\
\text { columnaris }\end{array}$ & - ve \\
\hline 5. & $57.24 \pm 2.07$ & $8.33 \pm 2.32$ & $830.17 \pm 139.65$ & $6.25 \pm 1.41$ & $69.70 \pm 11.57$ & $12.56 \pm 3.36$ & $1528.21 \pm 758.10$ & $6.88 \pm 0.64$ & A.tamarii & - ve \\
\hline 6. & $40.39 \pm 4.35$ & $9.58 \pm 3.69$ & $650.05 \pm 217.70$ & $5.17 \pm 0.89$ & $64.84 \pm 25.92$ & $12.70 \pm 1.00$ & $1461.29 \pm 1297.91$ & $7.81 \pm 0.92$ & $\begin{array}{c}\text { A.flavus var. } \\
\text { columnaris }\end{array}$ & $-v e$ \\
\hline 7. & $43.46 \pm 12.37$ & $7.44 \pm 1.86$ & $528.54 \pm 180.31$ & $6.00 \pm 1.68$ & $30.78 \pm 0.54$ & $11.23 \pm 1.47$ & $347.00 \pm 26.31$ & $6.22 \pm 1.54$ & A.sojae & - ve \\
\hline 8. & $51.09 \pm 14.73$ & $8.02 \pm 2.09$ & $674.53 \pm 213.62$ & $7.36 \pm 0.87$ & $35.03 \pm 2.38$ & $9.01 \pm 0.33$ & $385.80 \pm 35.62$ & $8.12 \pm 0.73$ & $\begin{array}{l}\text { A.flavus var. } \\
\text { columnaris }\end{array}$ & $-v e$ \\
\hline 9. & $67.54 \pm 31.49$ & $13.32 \pm 6.05$ & $576.48 \pm 225.00$ & $5.78 \pm 0.35$ & $56.95 \pm 4.95$ & $14.37 \pm 0.56$ & $905.29 \pm 39.09$ & $6.53 \pm 1.00$ & A.sojae & - ve \\
\hline 10. & $43.93 \pm 4.52$ & $11.36 \pm 2.98$ & $707.26 \pm 163.07$ & $4.60 \pm 0.38$ & $36.40 \pm 6.08$ & $10.85 \pm 1.45$ & $411.08 \pm 155.85$ & $8.19 \pm 0.96$ & A.tamarii & - ve \\
\hline 11. & $54.69 \pm 9.77$ & $8.82 \pm 1.39$ & $674.98 \pm 162.24$ & $6.64 \pm 0.46$ & $49.83 \pm 4.94$ & $12.05 \pm 4.72$ & $815.33 \pm 28.32$ & $7.77 \pm 1.02$ & $\begin{array}{l}\text { A.flavus var. } \\
\text { columnaris }\end{array}$ & $-v e$ \\
\hline 12. & $66.37 \pm 23.55$ & $9.80 \pm 3.26$ & $785.57 \pm 245.34$ & $4.92 \pm 0.59$ & $77.50 \pm 3.16$ & $12.48 \pm 0.82$ & $1108.08 \pm 84.43$ & $7.48 \pm 0.76$ & $\begin{array}{l}\text { A.flavus var. } \\
\text { columnaris }\end{array}$ & + ve \\
\hline 13. & $57.45 \pm 7.43$ & $5.10 \pm 1.43$ & $301.81 \pm 45.73$ & $2.69 \pm 0.55$ & $47.96 \pm 13.50$ & $12.77 \pm 3.07$ & $578.52 \pm 244.66$ & $9.05 \pm 1.37$ & A.flavus & + ve \\
\hline 14. & $43.06 \pm 3.63$ & $10.19 \pm 1.71$ & $450.59 \pm 90.98$ & $7.05 \pm 1.65$ & $31.34 \pm 6.80$ & $9.18 \pm 1.18$ & $345.23 \pm 139.36$ & $5.04 \pm 1.23$ & A.flavus & + ve \\
\hline 15. & $52.60 \pm 7.30$ & $3.63 \pm 0.49$ & $619.40 \pm 286.47$ & $4.74 \pm 0.39$ & $67.02 \pm 14.52$ & $13.55 \pm 1.76$ & $555.53 \pm 327.28$ & $4.96 \pm 1.66$ & A. parasiticus & $+v e$ \\
\hline 16. & $70.84 \pm 26.49$ & $8.58 \pm 1.39$ & $719.25 \pm 206.58$ & $6.70 \pm 1.35$ & $68.61 \pm 12.65$ & $10.14 \pm 2.71$ & $291.82 \pm 68.31$ & $6.57 \pm 2.10$ & A.niveus & + ve \\
\hline 17. & $66.20 \pm 8.72$ & $10.06 \pm 0.99$ & $730.21 \pm 49.52$ & $6.64 \pm 0.46$ & $45.63 \pm 6.92$ & $12.62 \pm 2.33$ & $617.24 \pm 207.70$ & $7.02 \pm 1.64$ & A.tamarii & - ve \\
\hline 18. & $46.18 \pm 4.34$ & $8.09 \pm 2.83$ & $585.20 \pm 114.19$ & $5.52 \pm 0.31$ & $36.33 \pm 9.95$ & $13.86 \pm 3.47$ & $595.86 \pm 244.88$ & $7.45 \pm 1.29$ & A.flavus & - ve \\
\hline 19. & $35.62 \pm 4.41$ & $9.21 \pm 2.09$ & $536.70 \pm 86.74$ & $4.59 \pm 0.80$ & $78.95 \pm 36.05$ & $15.43 \pm 8.14$ & $1191.28 \pm 709.73$ & $7.60 \pm 1.97$ & A.flavus & - ve \\
\hline 20. & $37.61 \pm 3.61$ & $10.14 \pm 1.65$ & $514.83 \pm 99.38$ & $7.37 \pm 0.75$ & $46.86 \pm 2.60$ & $11.72 \pm 0.23$ & $581.62 \pm 174.03$ & $7.74 \pm 0.24$ & A.tamarii & - ve \\
\hline
\end{tabular}

Values after \pm indicates standard deviations (SD) of five replications 
Fig. 1 Macroscopic and microscopic characteristics of A. flavus. A-B: colony features on PDA medium, front and reverse surface; $\mathrm{C}-\mathrm{D}$ : conidial heads and conidia; E-F: colony features on YESmedium, front and reverse surface ; $\mathrm{G}-\mathrm{H}$ : conidial heads and ascospore

PDA Medium

Front
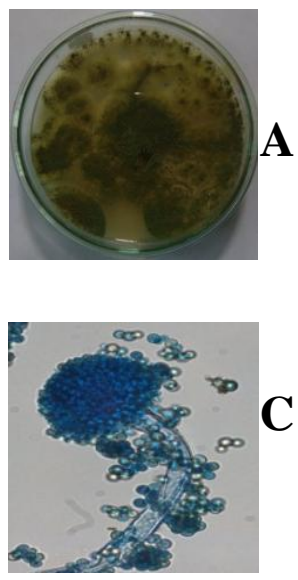

Reverse

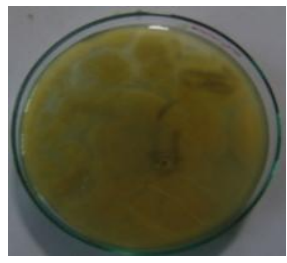

B

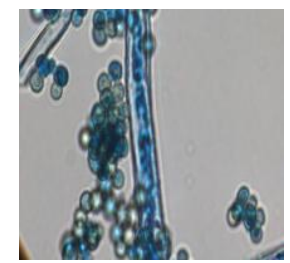

D
YES Medium

Front

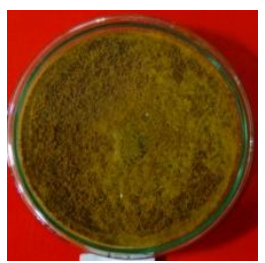

$\mathbf{E}$
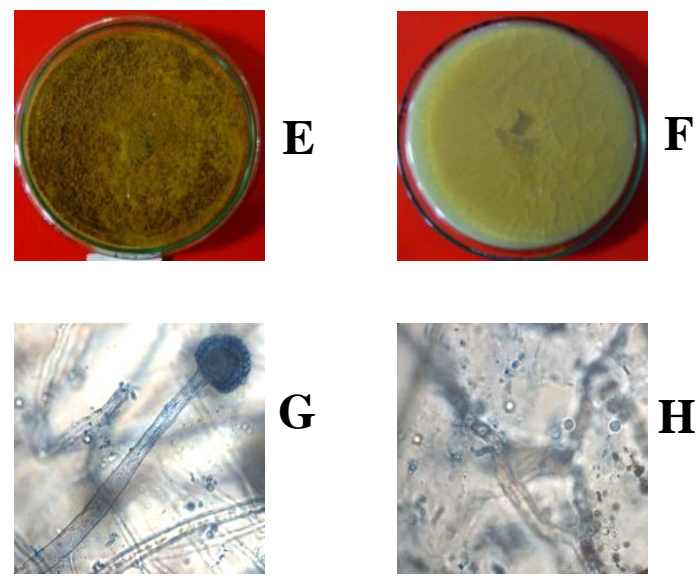

Reverse

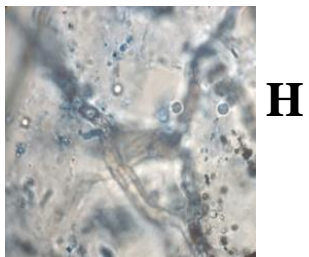

Fig. 2: Macroscopic and microscopic characteristics of $A$. tamarii . A-B: colony features on PDA medium, front and reverse surface; C-D: conidial heads and conidia; E-F: colony features on YESmedium, front and reverse surface ;G-H: conidial heads and ascospore

PDA Medium

Front
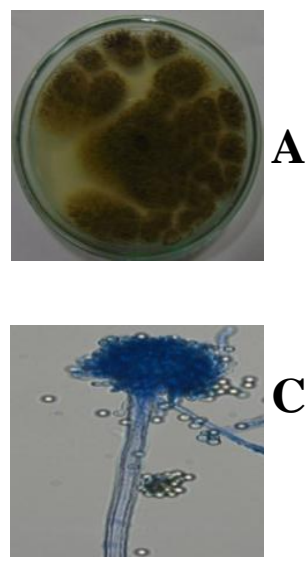

Reverse

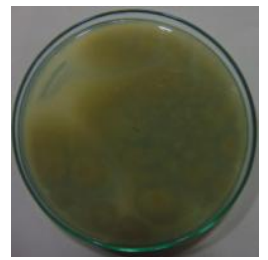

B

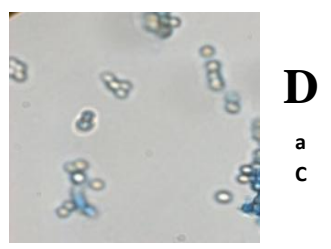

YES Medium

Front

Reverse
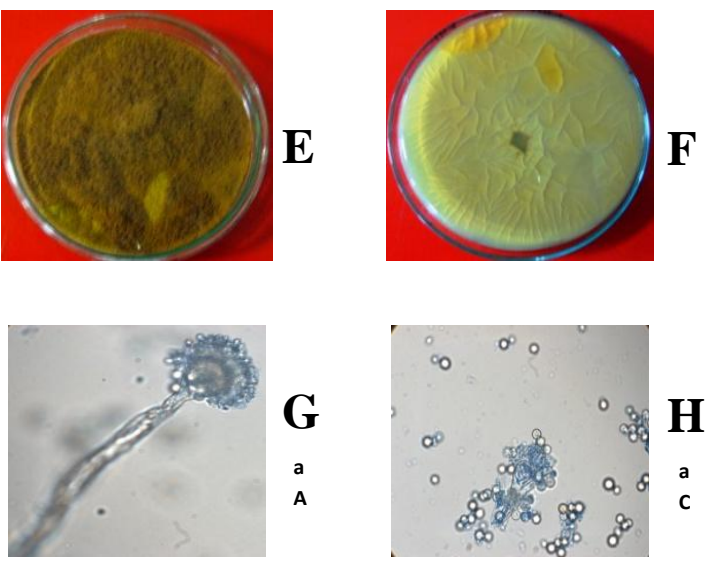
Fig.3 Macroscopic and microscopic characteristics of A. flavus var. columnaris. A-B: colony features on PDA medium, front and reverse surface; C-D: conidial heads and conidia; E-F: colony features on YES medium, front and reverse surface; $\mathrm{G}-\mathrm{H}$ : conidial heads and ascospore
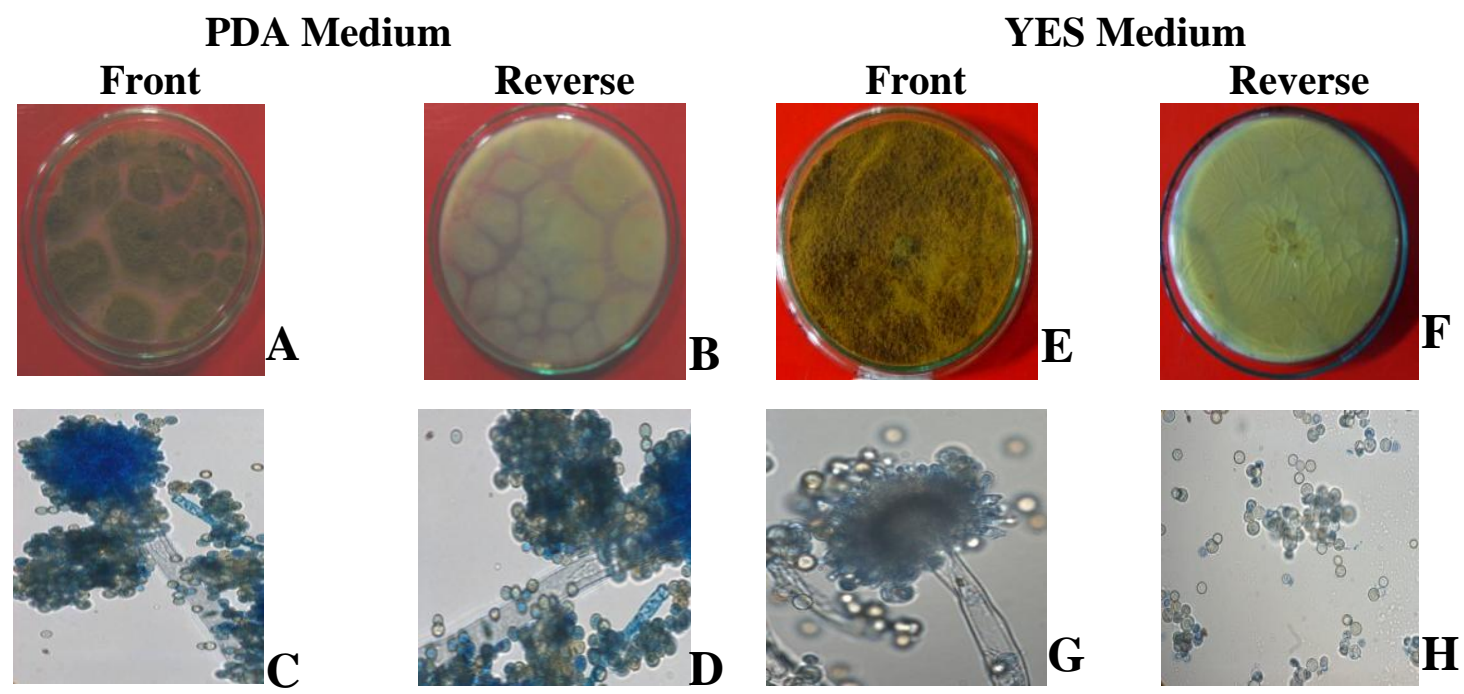

Fig.4 Macroscopic and microscopic characteristics of A. sojae. A-B: colony features on PDA medium, front and reverse surface; $\mathrm{C}$-D: conidial heads and conidia; E-F: colony features on YES medium, front and reverse surface; G-H: conidial heads and ascospore

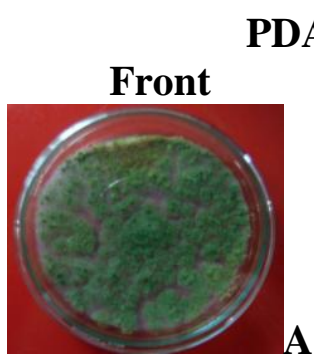

PDA Medium
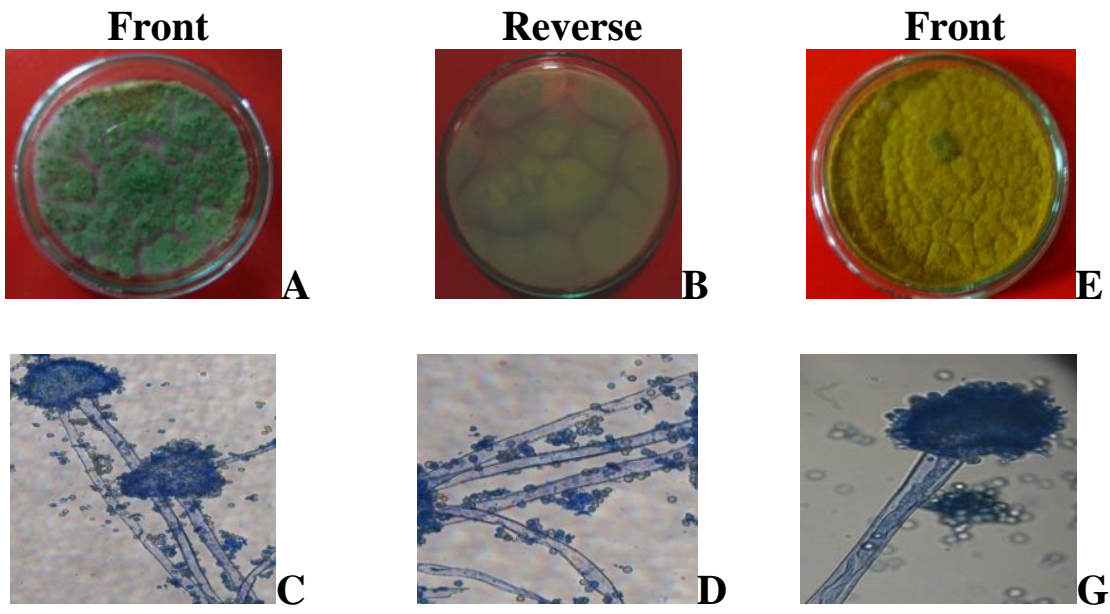

YES Medium
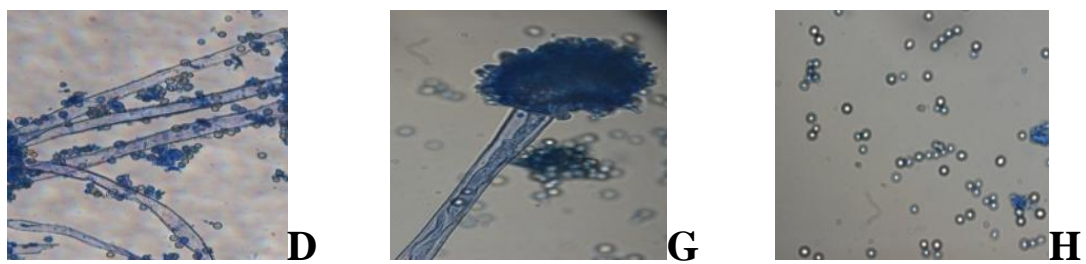
Fig.5 Macroscopic and microscopic characteristics of A. parasiticus A-B: colony features on PDA medium, front and reverse surface; C-D: conidial heads and conidia; E-F: colony features on YES medium, front and reverse surface ; $\mathrm{G}-\mathrm{H}$ : conidial heads and ascospore
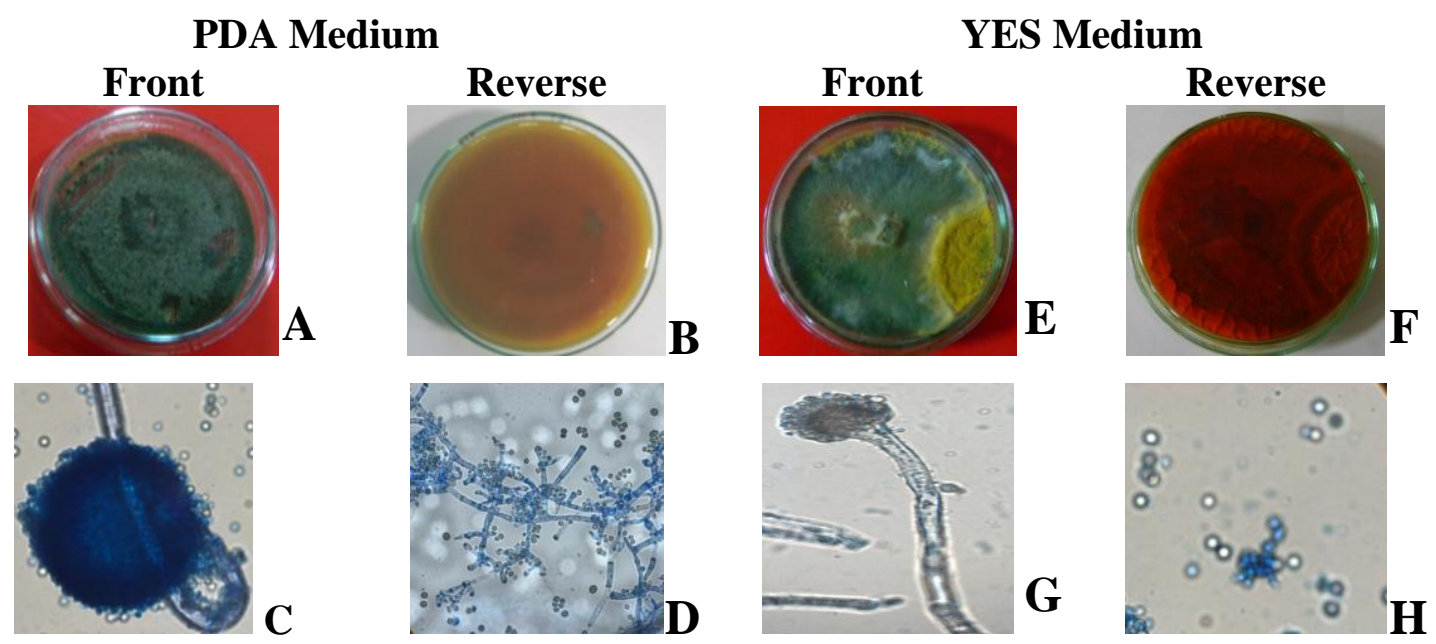

Fig.6 Macroscopic and microscopic characteristics of A.niveus. A-B: colony features on PDA medium, front and reverse surface; $\mathrm{C}-\mathrm{D}$ : conidial heads and conidia; E-F: colony features on YES medium, front and reverse surface ;G-H: conidial heads and ascospore.

PDA Medium
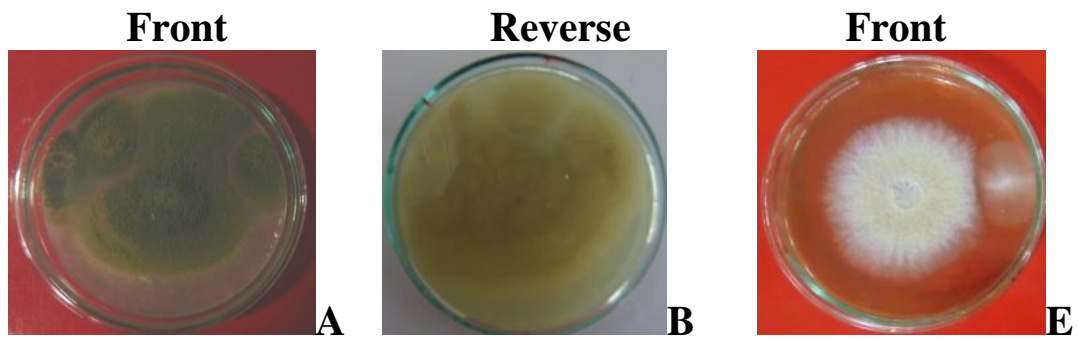

YES Medium
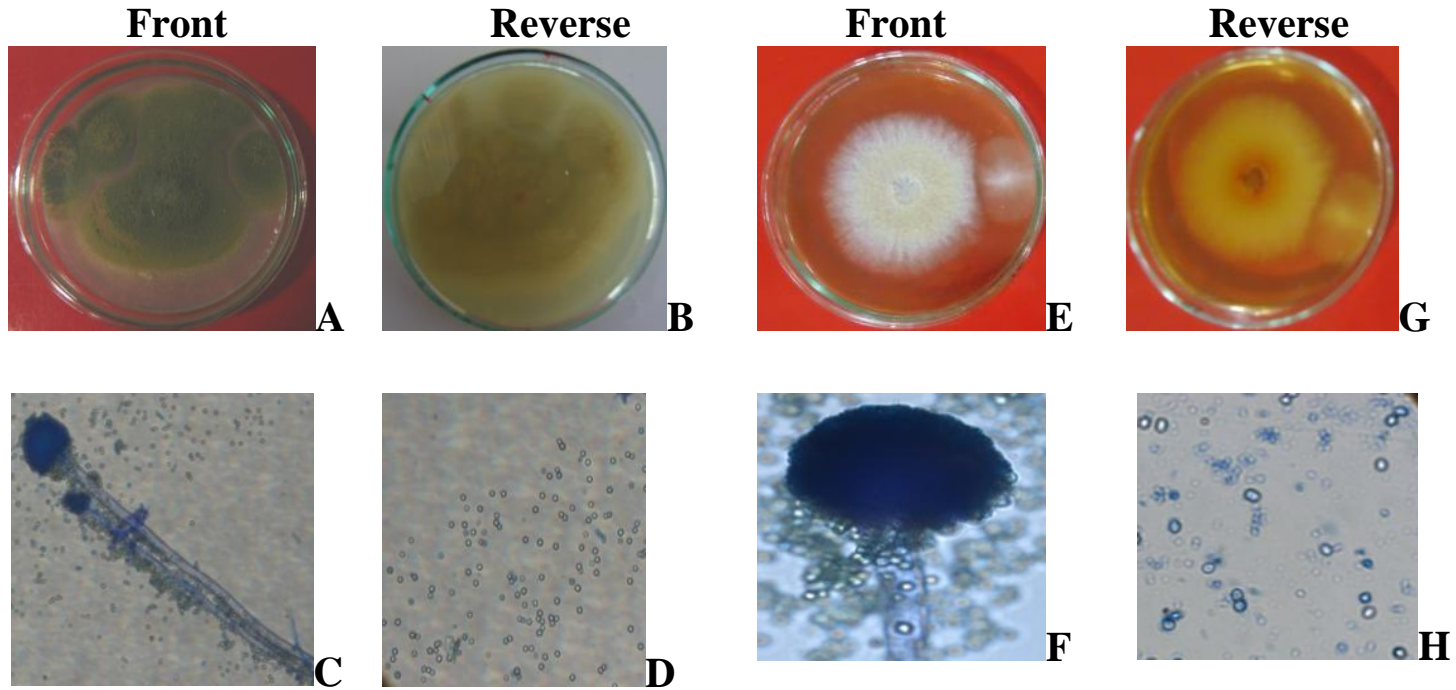
Fig. 7: Macroscopic and microscopic characteristics of A. fumigates. A-B: colony features on PDA medium, front and reverse surface; C-D: conidial heads and conidia; E-F: colony features on YES medium, front and reverse surface ; $\mathrm{G}-\mathrm{H}$ : conidial heads and ascospore

PDA Medium
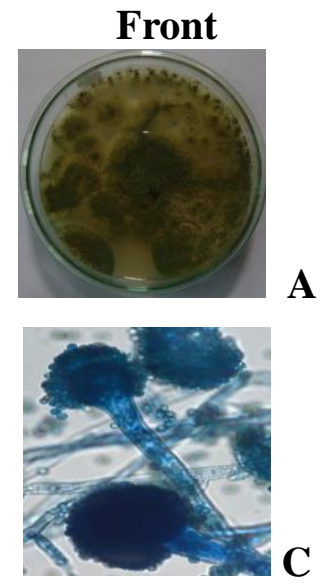

A
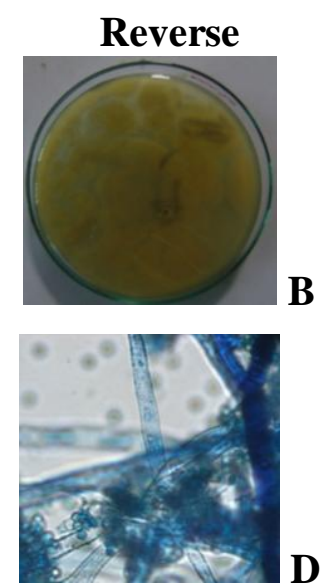

YES Medium
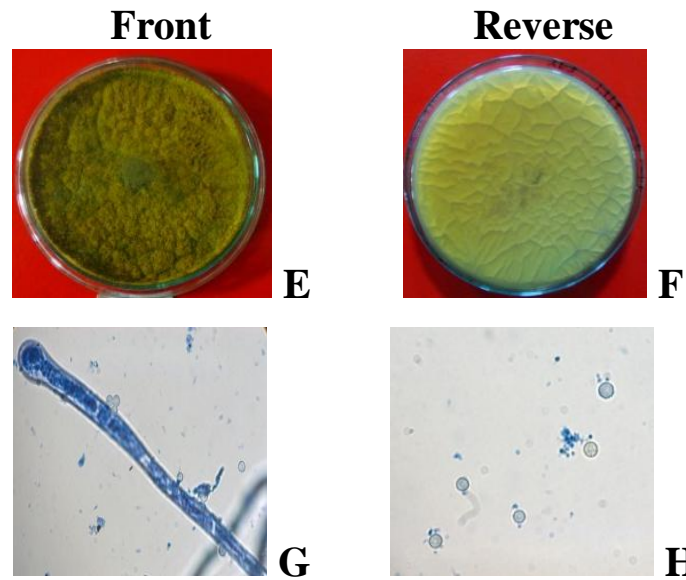

Fig. 8: Species distribution of Aspergillus isolates in percentage identified from groundnut Rhizosphere

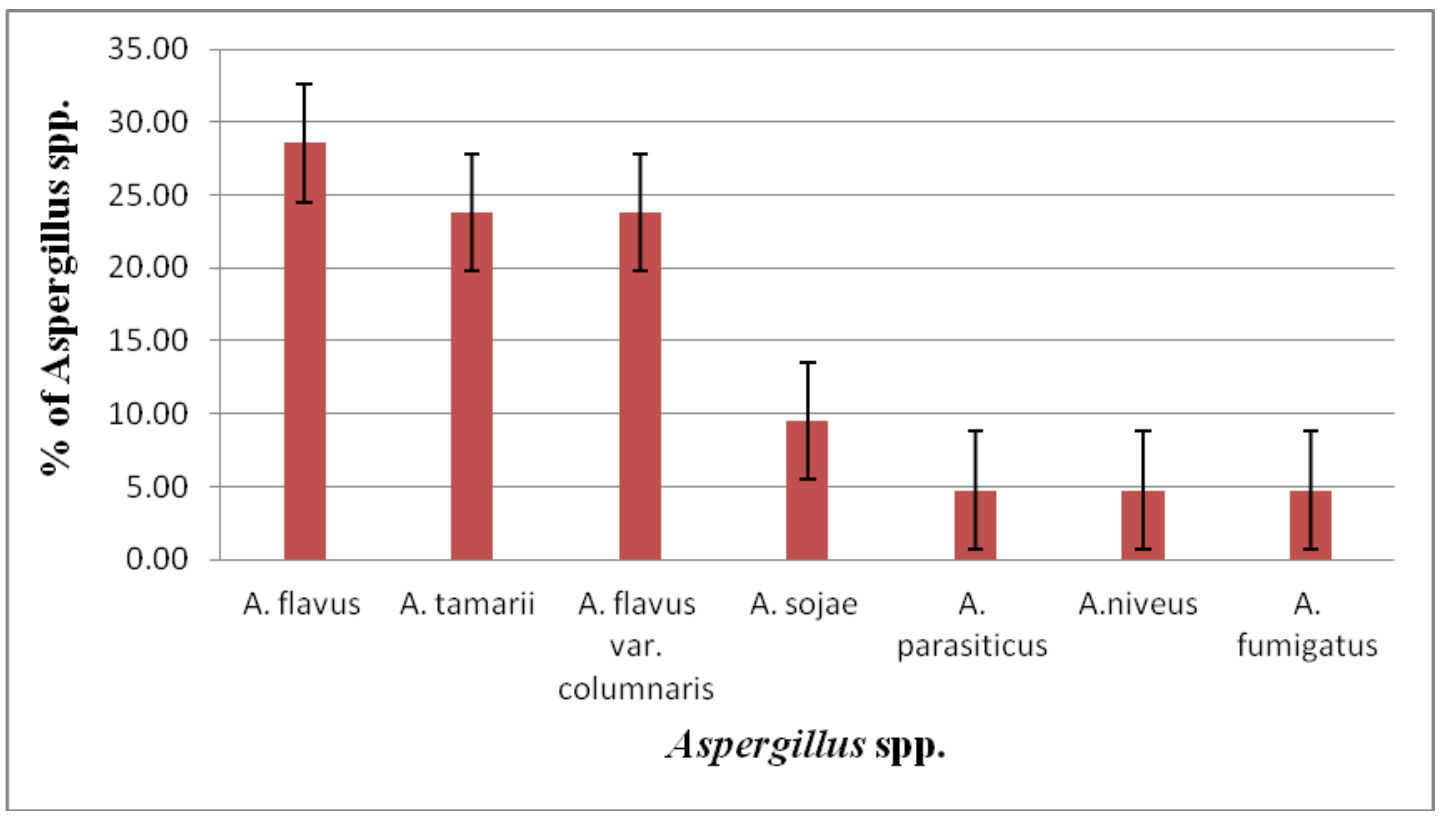

Screening of aflatoxin producing and non producing Aspergillus strains

To differentiate aflatoxin producing and aflatoxin nonproducing strains ammonium hydroxide vapor test was conducted. Results revealed that 08 fungal isolates viz. 2. RJDUPA-KUN-G-2，3. JAM-JKB-BHA-GG20, 12. RJD-UPA-KUN-TJ37A, 13. RJD-DHOPAR-GG37, 14. RJD-DHO-KAN-GG45, 15. JND-MAN-LIM-GG20 A, 16. JND-MANLIM-GG20 B, 21. JND- JAU -ISS-1 when 
exposed to ammonium hydroxide vapors, the reverse side of colonies turn from yellow to pink indicating the isolates produced toxic compound called aflatoxin. The remaining fungal isolates remain unchanged for reverse colony color (Table 2 ).

The A. flavus, A. tamarii, A. flavus var. columnaris, A. sojae, A. parasiticus, A.niveus, and $A$. fumigatus isolated in the present study are reported to be the most common fungal contaminant of groundnut rhizosphere. The fungal colonization was fast in most of the isolates and the mold presence on groundnut seed was also distinct. Among the different Aspergillus species obtained, the flavus species was found to be predominating in the study. Though the soil is a habitat for many types of fungal strains, only selected fungi have the ability to establish infection in the post harvest groundnut. The fungal contamination occurs not only from the field soil but also from field instruments, insects, pests, birds and storage methods. The wide spread occurrence of Aspergillus flavus showed the extent of pre-harvest and postharvest contamination occurring naturally (Kabir et al., 2013). Among the Aspergillus species obtained in the present study, the predominating fungal species found to be $A$. flavus $(28.57 \%)$ followed by, A. tamari (23.81\%), A. flavus var. columnaris $(23.81 \%)$, A. sojae (9.52\%), A. parasiticus (4.76\%), A. niveus (4.76\%) and A. fumigatus (4.76\%).

The results have shown that PDA and YES media are easy, simple and reliable as also recorded by Raper and Fennell (1965). No any increase or decrease trade was observed in microscopic character on both media. In most of isolates when vesicle diameter increase on YES medium, all other microscopic characters were found to be increase but it was not in all the isolates . Various reports have been published that used morphological characters as key identifying factors (Morya et al., 2009; Bandh et al.,
2012). A. flavus and A. tamari were dominating species isolated from all obtained isolates. Identifying character of Aspergillus flavus were yellow to green or dark green colony color and radiate heads with smooth conidiophore wall. Maximum isolates showed spot ring like flat conidiation on YES medium, while mix (circular or spot ring like flat) condition was seen among isolates on PDA medium. The YES medium is easy to prepare, relatively inexpensive, and is suitable for production of higher levels of aflatoxin than those reported for other media. For these reasons, YES medium appears to be suitable for both production of aflatoxin and for screening fungi for their ability to produce aflatoxins (Davis et al., 1966).

Saito and Machida (1999) developed a rapid method for identifying aflatoxin producing and non-producing strains of $A$. flavus and $A$. parasiticus, which may provide a useful prescreen for identifying non-toxigenic strains. In this method, the reverse side of colonies of aflatoxin producing Aspergillus strains on potato dextrose agar (PDA) medium turn from yellow to pink immediately after exposure to ammonium hydroxide vapor. In present study more than $60 \%$ of Aspergillus isolates belongs to either Aspergillus flavus or Aspergillus parasiticus sp. producing aflatoxin in present investigation. Besides that, A. fumigates and A. niveus also showed positive biochemical test for aflatoxin production. Further the level of quantification of aflatoxin production need to be conformed for newly identified Aspergillus spp. The percentage of aflatoxigenic strains of Aspergillus flavus has been shown to vary with the nature of substrate and environmental factors. The incidence of aflatoxigenic Aspergillus flavus strains was higher in peanuts $(69 \%)$ than in wheat $(13 \%)$ (Vaamonde et al., 2003). Abdi et al (2014) had found Aspergillus flavus contamination in peanut kernels ranging from $20 \%$ to $48 \%$ varying with the region and place of sample 
collection.

In conclusion, characterization of Aspergillus associated with aflatoxic and non aflatoxic isolates from groundnut seed, cake and soil showed diversity in groundnut rhizosphere. The study showed that earlier detections can be made by simple traditional identifications using macro and micro morphological fungal features rather than adopting the time and cost consuming molecular identification techniques. Their earlier detection may help to adopt physical management practices and to initiate some biocontrol methods to avoid afla-toxinogenic contamination in groundnut and maintain seed quality for export.

\section{References}

Abdi, M. and Alemayehu, C. 2014. Incidence of Aspergillus contamination of groundnut (Arachis hypogaea L.) in Eastern Ethiopia. Afr. J. Microbiol., 8(8):759-765.

Anonymous (2013). Annual Report. Agricultural and Processed Food Products Export Development Authority, Ministry of Commerce and industry, Govt. of India, New Delhi.

Bandh, S.A., Kamili, A.N. and Ganais, B.A. 2012. Identification of some aspergillus species isolated from dal lake, Kashmir by traditional approach of morphological observation and culture. Afr. J. Microbial. Res., 6(29): 5824-5827.

Davis, N. D., Diener, U. L. and Eidridge, D. W. 1966. Production of aflatoxins B1 and G1 by Aspergillus flavus in a semisynthetic medium. Appl. Microbiol., 14(3): 378-380.

Diba, K., Kordbacheh, P., Mirhendi, S. H., Rezaie, S., and Mahmoudi, M. 2007. Identification of Aspergillus sp. using morphological characteristics. Pak. J. Med. Sci., 23, 867-872.
Gams, W., Christensen, M., Onions, J.P., and Samson, R.A., 1985. Advances in penicillium and aspergillus systematic, Springer.

Johnston, A. and Booth, C., 1983. Commonwealth Agricultural Bureaux. Plant pathologist's pocketbook.

Kabir, A., Kanchan, K., Jaiswal, S., Keshari, S. and Mehta, A. 2013. Isolation of toxigenic mycoflora from potential edible sources and study of the susceptibility to produce aflatoxin. Int. J. Pharm. Bio. Sci. 4(1):86-94.

Klich, M.A. 2002. Biogeography of Aspergillus species in soil and litter. Mycologia. 94, 21-27.

Klich, M.A. 2007. Environmental and developmental factors influencing aflatoxin production by Aspergillus flavus and Aspergillus parasiticus. Mycosci. 48, 71-80.

Kumeda, Y. and Asao, T. 2001. Heteroduplex panel analysis, a novel method for genetic identification of Aspergillus section Flavi strains. Appl. Env. Microbiol., 67: 4084-4090.

Manjusha, C. and Anita, P. 2013. Comparison of microscopic, macromorphological and aflatoxin producing capabilities of Aspergillus species associated with rhizosphere of groundnut (A. hypogaea L.). J. Chem. Bio. Phy. Sci. Sec. B., 3(2):1327-1337.

Morya, V.K., Kmal, and Yadav, D. 2009. Diversity of indigenously isolated aspergilli from soil of monoculture teak forest. Res. J. Soil Biol. 1(3): 7783.

Okuda, T., Klich, M. A., Seifert, K. A. and Ando, K. 2000. Integration of modern taxonomic methods for Penicillium and Aspergillus classification (R.A. Samson and J.I. Pitt, Eds.), Hardwood Academic Publishers, Reading, UK, 83-100.

Pitt, J. I., Samson, R. A. and Frisvad, J. C. 
2000. Integration of modern taxonomic methods for Penici-llium and Aspergillus classification (R.A. Samson and J.I. Pitt, Eds.), Hardwood Academic Publishers, Reading, UK, 950.

Raper, K. B. and Fennell, D. I. 1965. Description and morphology. The genus Aspergillus. The Williams \& Wilkins Company. United States of America: The Waverly Press, 17-29.

Saito, M. and Machida, S. 1999. A rapid identification method for aflatoxinproducing strains of A. flavus and $A$. parasiticus by ammonia vapor. Mycosci., 40: 205-211.

Salleh, B. and Sulaiman, B. 1984. Fusaria associated with naturally diseasedplants in Penang. Journal of Plant Protection in the Tropics, 1, 47-
53.

Schindler, A. F., John, G. P. and Eisenberg, W. V. 1967. Aflatoxin Production by Aspergillus favus as Related to Various Temperatures. Appl. Microbiol., 15(5): 1006-1009.

Vaamonde, G., Patriarca, A., Pinto, V.F., Comerio, R. and Degrossi, C. 2003. Variability of aflatoxin and cyclopiazonic acid production by Aspergillus section Flavi from different substrates in Argentina. Int. J. Food Microbiol.,88:79-84.

Waksman, S.A. and Fred, E.B. 1922. A tentative outline of the plate method for determining the number of microorganisms in the Soil. J. Soil Sci. 14(1):27-28.

\section{How to cite this article:}

Bharose, A.A., H.P. Gajera, Darshna G. Hirpara, V.H. Kachhadia and Golakiya, B.A. 2017. Morphological Credentials of Afla-Toxigenic and Non-Toxigenic Aspergillus Using Polyphasic Taxonomy. Int.J.Curr.Microbiol.App.Sci. 6(3): 2450-2465. doi: https://doi.org/10.20546/ijcmas.2017.603.279 